\title{
The Effect of Experienced Incivility From Supervisor and Coworkers Towards Instigated Incivility in Daily Level Among Nurses
}

\author{
Metty Verasari ${ }^{1, a^{*}}$ and Prof. Madya Hazalizah Hamzah ${ }^{1, b}$ \\ 1 Universiti Pendidikan Sultan Idris, Perak, Malaysia; 2University Pendidikan Sultan Idris, Perak, Malaysia \\ a metty@mercubuana-yogya.ac.id; b hazalizah@fppm.upsi.edu.my \\ ${ }^{*}$ Corresponding Author \\ Whatsapp Number [+6281271914653]
}

How to Cite: Verasari, M. \& Hamzah, H. (2019). The Effect of Experienced Incivility from Supervisor and Coworkers towards Insitgated Incivility in Daily Level among Nurses. International Journal for Educational and Vocational Studies, 1(4) 359-363

\section{ARTICLE HISTORY}

Received: 15 May 2019

Revised: 8 June2019

Accepted: 23 July 2019

\section{KEYWORDS}

Smart egg puzzle game; Understanding the concept of geometry; Early childhood;

\section{ABSTRACT}

Workplace Incivility is a common phenomenon in workplaces in many organization. Understanding the concept of workplace incivility to hospital managers and other health care organizations. The necessary antecedent of workplace incivility consisted of the presence of two or more people, with one or more as the source of the incivility, and another or others as its target in the workplace. This study aimed to understand the effect of experienced incivility from nurse's supervisor and coworker in hospital. Its also try to figure out instigated incivility pattern in daily level. The methodology to analyze is diary study between 3 days on 102 nurses Sumatra, Indonesia. Results of this study indicate a differences in the effect of experienced incivility on instigated incivility in terms of measurements per days. Simultaneously experienced incivility by supervisors and coworkers has an influence on instigated incivility in the first day, and second day from supervisor incivility, but on experienced incivility from coworkers influenced in second day, and third day to instigated incivility.

This is an open access article under the CC-BY-SA license.

\section{INTRODUCTION}

Workplace Incivility is a common phenomenon in many organisation's workplace. Zhou (2014), explain that workplace incivility as an uncivil behavior, which is characterized by the low intensity, the intention to harm others, and violence of norms in the respected workplace. The example of behavior is expressing rude comments, using humiliating tone, and talking unprofessionally to someone. Altough incivility gives a disadvantage, but only few organization that consider, report, and investigate it. Many organizations don't even realize it until it changes the culture. That's why the impact of incivility is not only on national culture but also industrial culture and organization tends to influence perceptions and reactions to incivility (Schilpzand, Pater, \& Erez, 2016). This shows that incivility has spread and become a phenomenon that has negative consequences. Although the number of workplace incivility has been increased, but in Indonesia, study about incivility is newest issues (Christlevica, Joan, \& Ricky, 2016; Sleem \& Seada, 2017).

Nurses in the healthcare center are the vital parts. They continuously work for 24 hours to take care and - interact with patients (Asmuji, 2014). They are required to give good service and they are such a big hope for the patients to obtain maximum healthcare service (Prayogi, 2014). Unfortunately, the work environment of the nurses is often accompanied by various types of mistreatment, which is may be from doctors, other nurses, patients or supervisors (Beattie \& Griffin, 2014; Vagharseyyedin, 2015). Unconsciously, nurses are influenced by negative interpersonal behavior in their work environment, and it will be ignored by managers because workplace incivility has a low intensity (Vagharseyyedin, 2015).

The number of workplace incivility in healthcare settings has been increased and it would give impact on nurses to delivering healthcare services. Nurses has been abused verbally by the supervisor and collegues (Luparell, 2011 ), but in 2016 , more than $73 \%$ of nurses at emergency departments in the United States feel that violence is part of their work so they are reluctant to report the incident (Christlevica et al., 2016). Incivility has potentially detrimental effects on healthcare providers and patient safety (Elmblad, Kodjebacheva, \& Lebeck, 2014; Brooks, 
2017). Workplace deviance is a common response to workplace aggression. Specifically, victims with low task interdependence will be more vulnerable to reply abusive behavior, at higher level triggers (Hershcovis, Parker, Reich, \& Bozeman, 2012).

The greater incivility frequency and prepetrator power are associated with greater emotionality (negative emotions, guit, sadness, fear/anxiety, and disgust) and it will increased reciprocation (Bunk \& Magley, 2013). Nurses that experienced incivility from supervisor and coworkers has significant relationship with instigated incivility (Torkelson, Holm, Bäckström, \& Schad, 2016). But, incivility from coworkers has more the strongest relationship with instigated incivility than supervisor. The reason is individu more likely to act in a deviant manner if they had information about deviant action by colleagues, particularly if group cohesion was high (Ferguson \& Barry, 2011).

Experieced worklplace incivility is related to work satisfaction and general job satisfaction's decrease (Bunk \& Magley, 2013); and more job stress for employees who reported having less emotional support (Miner, Settles, Pratt - Hyatt, \& Brady, 2012); because emotion, especialy emotional exhaustion plays a mediating role between coworker incivility and job satisfaction (Hur, Kim, \& Park, 2015). In other side, social support from coworkers will decreased instigated incivility, but when variable experienced incivility was add, it will be increased instigated incivility (Miner et al., 2012; Holm, Torkelson, \& Bäckström, 2015). Based on previous research, we can draw temporary conclusion that social support and job satisfaction play an important role in working incivility.

Incivility is in several ways related to the power position of the instigator and social power theory (Torkelson et al., 2016). Torkelson et al. (2016) also explained that the instigator status could be explained in two ways. Based on that, this research will focused on workplace incivility from supervisors and coworkers.

First, it is common for the instigator status to be found higher up in the organizational hierarchy. In an organizational context, social power theory posits that employees of lower social status, such as those lower in the organizational hierarchy or those who are part of low-status groups in the workplace, may be more susceptible to incivility from higher status employees. In this way, the incivility process often starts from the top of the organization when high-status employees enact uncivil behaviours towards lower status employees (Torkelson et al., 2016).

Second way, incivility may take different forms that are related to the instigator's power position in the organization. Pearson (2010) found that incivility that starts from the bottom of the organizational hierarchy and directs upwards is exerted in other ways than incivility exerted in the opposite direction,such as subtle forms of sabotage. the target's perception of bad behaviour may be linked to the power position of the instigator (Torkelson et al., 2016). A study by Cortina and Magley (cited in Torkelson et al. 2016) revealed that employees experienced rude treatment in a more negative way if it was initiated by someone who had a higher position. In the light of the relationship between incivility and power position, it is relevant to investigate incivility from co-workers and incivility from supervisors separately.

Its necessary to discussed about the variables which is included in this study, that is experienced incivility and instigated incivility in daily life. In the current study, the conceptual framework is illustrated below (Figure 2.1).

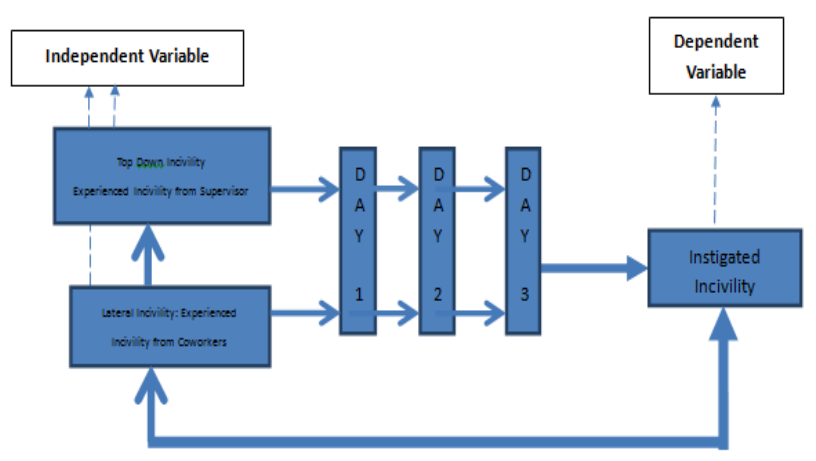

Figure 1. Theoritical Framework of Workplace Incivility among Nurse

\section{METHOD}

The population of this study will be taken from the Regional General Hospital in Special Region of South Sumatera, Indonesia. Purposive sampling method is used as the sampling method by categorizing the subjects (1) a nurse with nursing certificate (2) willing to be a repondent of this study, (4) having working period more than 2 years, (5) minimum age of 20 years, male or female, and is a nurse who has been appointed as permanent employee at the hospital, (6) understanding the instruction in filling in questionnaire in this research, and willing to follow research process for three consecutive days. Before the respondents to be a subject of this study, 150 nurses that fulfill the category must be following a screening test by filling out General Hospital Incivility (GHI) and finally 102 nurses could be to sample of this research. The result a GHI is 0.865 , and $\mathrm{V}=1.00$ ( $\mathrm{X} \geq 0.66$, its mean relevant), with the critical value of CVR is 0.496. Its mean that GHI Scale could be valid and reliable to be a screening test for this study.

Table 1. Distribution Respondent by Gender

\begin{tabular}{lll}
\hline \multicolumn{1}{c}{ Charateristics } & \multicolumn{1}{c}{ Category } & $\%$ \\
\hline \multirow{2}{*}{ Gender } & Male & 28 \\
& Female & 72 \\
\hline \multirow{2}{*}{ Working Periods } & $<3$ years & 23 \\
& years & 31 \\
& $>5$ years & 46 \\
\hline
\end{tabular}

A third way in which incivility also related the power of 


\begin{tabular}{llc}
\hline & Emergency departements & 34 \\
Nursing Department & Intensive Care Unit & 14 \\
& Outpatients & 6 \\
& Inpatients & 46 \\
\hline
\end{tabular}

Based on data from the respondent's distribution, it was seen that the subjects of the study consisted of 102 people, with nurses who were mostly respondents were women $(71.57 \%)$, most of them consisted of nurses who worked in inpatient units $(46.08 \%)$, and had years of service more than 5 years $(46.08 \%)$.

\section{MEASURES}

a. Experienced Incivility From Supervisor and Coworkers

The scale from Jiménez, Bregenzer, Leiter, \& Magley (2018) consists of eight aitem measure the behavior of workgroup supervisors and coworkers, respectively (e.g., "Gossiped about you or your colleagues"). Answer scales range used only two answered Yes and No. The result of Conbrachs Alpha is $0.824(\alpha \geq 0.6)$, its mean that thid aitem is reliable (Kerlinger, 1979). With the significance more then 95\%. For the content validity this instrument used CVR from Lawshe (1975) cited in Azwar (2012), with the critical value 0.496 and value of CVR $0.82-1.00$ ( $\mathrm{X} \geq 0.66$, its mean relevant). The result of content validity experienced incivility from supervisor and coworkers is valid.

b. Instigated Incivility

This item adapted from Jiménez et al. (2018), wit Yes and No answered, because measuring dailiy instigated incivility. The result from Validity and Reliability test, $\alpha$ is 0.934 and the critical value of CVR is 0.496 with $\mathrm{V}=0.82-1.00$ ( $\mathrm{X} \geq$ 0.66 , its mean relevant). From the validity and reliability test, explained that eight items of instigated incivility is valid and reliable.

Table 2. Effect of experienced incivility to instigated Incivility

(day 1, 2, and 3).

\begin{tabular}{|l|c|c|c|c|c|c|}
\hline \multirow{2}{*}{} & \multicolumn{2}{|c|}{ Day 1 } & \multicolumn{2}{c|}{ Day 2 } & \multicolumn{2}{c|}{ Day 3 } \\
\cline { 2 - 7 } & B & sig & B & sig & B & Sig \\
\hline $\begin{array}{l}\text { Experienced Incivility } \\
\text { from Supervisor }\end{array}$ & 0.109 & 0.037 & 0.334 & 0.000 & 0.115 & 0.288 \\
\hline $\begin{array}{l}\text { Experienced Incivility } \\
\text { from Coworkers }\end{array}$ & -0.30 & 0.758 & 0.197 & 0.099 & 0.261 & 0.011 \\
\hline
\end{tabular}

a. Dependent Variable: Instigated Incivility

\section{RESULTS AND DISCUSSION}

The results of the analysis (Table 3 ) indicate that there are differences in influence between experienced incivility from supervisors and coworkers on instigated incivility on the first, second, and third days. On the first day, the significance test results obtained sig. $0.037(p<0.05)$, and second day was sig. $0.000(p<0.005)$ which means that experienced incivility from supervisor, has a significant effect on instigated incitivity. But on the third day, the significance test results obtained sig 0.2888 ( $p>0.05)$,

which means that experienced incivility from supervisor has no significant effect to the instigated incitivity.

Based on that results, there are differences effect of experienced incivility from supervisors on instigated incivility on measurements of days 1 and 2 . On the first and second days, there is an influence between experienced incivility from supervisors and instigated incivility. Whereas on the third day, there was no significant effect between experienced incivility from supervisors and instigated incivility on nurses. This might be explained by "Status Model Instigator's theory" (C. M. Pearson, Andersson, \& Porath, 2000). Incivility tends to flow down, because the perpetrator of incivility has a status that three times higher than the target. In the end, nurses considered that violence as part of their work. (Christlevica et al., 2016)

The value of the influence of experienced incivility from coworkers on instigated incivility can also be analyzed in table 1 . On the first day, the results of significance test was sig. $758(p>0.05)$ which means that experienced incivility from coworkers have no significant effect on instigated incivility. But in the second day, the significance value was sig.0.049 ( $p<0.05)$; and on third day, the significance value was sig.0.011 $(p<0.05)$, which means that experienced incivility from coworkers has a significant effect on instigated incivility.

The results of data analysis on the influence of experienced incivility from coworkers and instigated incentives, shows a different pattern with the results of data analysis on the influence of experienced incivility from supervisors on instigated incivility on the first, second and third days. In experienced incivility of coworkers against instigated incivility, there was no significant effect on the first day, but on the second and third days there was an influence of experienced incivility from coworkers on instigated incivility.

This situation might be explained by "models of social support" (Cohen and Wills, 1985). Social support buffers, protects, individuals well being when they are under stress. Social support can reduce negative effects of stressful events with communicates that they are valued and accepted (Miner et al., 2012). But, this can worsen if the belief in the existence of social support is not fulfilled. Individu can act in a deviant manner, especially if they had information about deviant action by colleagues, particularly if group cohesion was high (Ferguson \& Barry, 2011).

Table 3. The effect of experienced incivility from supervisor and

coworkers on insitigated incivility days 1,2 and 3 .

\begin{tabular}{rcccccc}
\hline \multirow{2}{*}{ Model } & \multicolumn{2}{c}{ Day 1 } & \multicolumn{2}{c}{ Day 2 } & \multicolumn{2}{c}{ Day 3 } \\
\cline { 2 - 7 } & $\mathrm{F}$ & Sig. & $\mathrm{F}$ & $\mathrm{Sig}$ & $\mathrm{F}$ & Sig \\
\hline Regression & 2.551 & 0.083 & 14.228 & 0.000 & 5.999 & 0.003 \\
\hline a. & Dependent Variable: Instigated Incivility & \\
b. & Predictors: (Constant), experienced incivility from \\
& coworkers, experienced incivility from supervisor
\end{tabular}


experienced simultaneously incivility by supervisors and coworkers on instigated incivility in days 1,2 and 3 . We found that on the first day, there is no significant effect on the instigated incivility ( $\mathrm{F}=2,551$ with sig. $0.083(\mathrm{p}>0.05))$. But on the second $(\mathrm{F}=14,228$ with sig. $0.000(\mathrm{p}<0.05))$ and third day $(\mathrm{F}=5.999$ with sig. $003(\mathrm{p}<0.05))$, there was significant effect of experienced incivility simultaneously by supervisors and coworkers on instigated incivility.

In accordance with the first research question, "is there a difference in the effect of experienced incivility from supervisors and coworkers on instigated incivility seen from the level per day?" The answer is there has a differences in influence per day. Statistically the variable experienced simultaneously incivility by supervisors and coworkers has an influence on instigated incivility in the second and third days, but not having an influence on the first day.

Based on the results of hypothesis testing, there is the differences in influence between experienced incivility from supervisors and coworkers on instigated incivility, on the first, second and third days. This finding is in accordance with Holm, Torkelson, \& Bäckström's (2015) research on workplace incivility using a cross sectional study, that there is a relationship between experienced incivility from supervisors and coworkers towards instigated incivility.

Zhou (2014), explain that experienced incivility from supervisors had a contribution of $12 \%$ to nurse's instigated incivility behaviour. Whereas experienced incivility from coworkers contributed $15 \%$ to instigated incivility. However, in this study, we found that experienced incentives from supervisors and coworkers contributed in different days to the behavior of instigated incivility.

On the first day, experienced incivility of supervisors and coworkers contributed $3.0 \%$ to instigated incivility, while the remaining (97\%) was explained by other variables outside of this research model. Then on the second day, experienced incivility from supervisors and coworkers contributed $20.8 \%$ to the instigated incivility variable, while the remaining $(79.2 \%)$ was explained by other variables outside the research model. Then on the third day, the variable experienced incivility of supervisors and coworkers contributed as much as $9.0 \%$ to instigated incivility, while the other (91.0\%) was explained by other variables outside of this research model.

Based on the explanation, it can be concluded that there are differences in the level of instigated incivility after experienced incivility from supervisors and coworkers per day (days 1, 2 and 3). DeLonghiss, Hemphill, and Lehman (1992), explain that the results of a diary study have the potential to fluctuate every day. When the measurement is made daily on a week, the mood changes are very influential. The same thing was expressed by Ohly, Sonnentag, Niessen, \& Zapf (2010), which states that every human being experiences mood changes every day, and this will cause changes in work performance from day to day. Therefore the measurement of experienced incivility needs to be done on a level per day basis, to see the difference in impact caused by workplace incivility itself (Herchovis, 2010 cited in Shapiro, 2013).

The difference in incivility, between supervisors and colleagues greatly influences the impact of instigated incivility behavior. "The Escalating Spiral of Incivility" from Pearson et al. (2000) explains the influence between experienced incivility from supervisors and coworkers on instigated incivility. A worker who has experienced incivility can intentionally reply to the behavior with counter-intention which leads to an increased chain reaction to more aggressive behavior. Pearson et al. (2000) also explained that the difference in the impact of experienced incivility also affected the instigator status. The status has a crucial role, when instigators have more power than targets, targets may feel helpful to fend off this mistreatment.

\section{CONCLUSION}

In this research, we find that experienced incivility by supervisors and coworkers has an influence on instigated incivility with the different results per day. The results have different patterns on instigated incivility between the experienced incivility from coworkers and from supervisors on the first, second and third days. Inexperienced incivility from coworkers has no significant effect on the first day, but there was an influence on instigated incivility in the second and third days. While experienced incivility from the supervisor, there was a 
significant instigated incivility's effect on the first and second days but has no influence on the third day. The results of this study indicate a differential effect of experienced incivility on instigated incivility in terms of measurements per day.

\section{REFERENCES}

Beattie, L., \& Griffin, B. (2014). Day-level fluctuations in stress and engagement in response to workplace incivility: A diary study. Work \& Stress, 28(2), 124-142. https://doi.org/10.1080/02678373.2014.898712

Bunk, J. A., \& Magley, V. J. (2013). The role of appraisals and emotions in understanding experiences of workplace incivility. Journal of Occupational Health Psychology, 18(1), 87-105.

https://doi.org/10.1037/a0030987

Christlevica, M., Joan, G., \& Ricky, D. (2016). Pengalaman Kekerasan Pada Perawat Instalasi Gawat Darurat. Jurnal Skolastik Keperawatan, 2(1), 20.

Elmblad, R., Kodjebacheva, G., \& Lebeck, L. (2014). Workplace Incivility Affecting CRNAs: A Study of Prevalence, Severity, and Consequences With Proposed Interventions. AANA Journal, 82(6), 437-445.

Ferguson, M., \& Barry, B. (2011). I Know What You Did : The Effects of Interpersonal Deviance on I Know What You Did: The Effects of Interpersonal Deviance on Bystanders. Journal of Occupational Health Psychology, 16(1), 80-94. https://doi.org/10.1037/a0021708

Hershcovis, S., Parker, S. K., Reich, T., \& Bozeman, J. (2012). The relationship between workplace aggression and target deviant behaviour: The moderating roles of power and task interdependence. Work and Stress, 26(1), 1-20.

https://doi.org/10.1080/02678373.2012.660770

Holm, K., Torkelson, E., \& Bäckström, M. (2015). Models of Workplace Incivility: The Relationships to Instigated Incivility and Negative Outcomes. BioMed Research International, 1-10.

https://doi.org/10.1155/2015/920239

Hur, W., Kim, B., \& Park, S. (2015). The Relationship between Coworker Incivility, Emotional Exhaustion, and Organizational Outcomes, The Mediating Role of Emotional Exhaustion. Human Factors and Ergonomics in Manufacturing \& Service Industries, 25(6), 701-712. https://doi.org/10.1002/hfm.2058

Jiménez, P., Bregenzer, A., Leiter, M., \& Magley, V. (2018). Psychometric properties of the German version of the workplace incivility scale and the instigated workplace incivility scale. Swiss Journal of Psychology, 77(4), 159-172.

https://doi.org/10.1024/1421-0185/a000213

Luparell, S. (2011). Incivility in Nursing: The Connection Between Academia and Clinical Settings. American
Association of Critical-Care Nurses, 31(2), 92-96. https://doi.org/10.4037/ccn2011171

Miner, K. N., Settles, I. H., Pratt - Hyatt, J. S., \& Brady, C. C. (2012). Experiencing Incivility in Organizations, The Buffering Effects of Emotional and Organizational Support. Journal of Applied Social Psychology, (Februari), 340-372.

https://doi.org/10.1111/j.1559-1816.2011.00891.x

Ohly, S., Sonnentag, S., Niessen, C., \& Zapf, D. (2010). Diary Studies in Organizational Research: An Intruduction and Some Practical Recommendations. Journal of Personnel Psychology, 9(2), 79-93. https://doi.org/10.1027/1866-5888/a000009

Pearson, C. (2010). The Cost of Bad Behavior, How Incivility Is Damaging Your Business and What to Do about It. Human Resource Management International Digest, 18(6).

https://doi.org/10.1108/hrmid.2010.04418fae.002

Pearson, C. M., Andersson, L. M., \& Porath, C. L. (2000). assesing and attacking workplace incivillity.pdf. Organnizational Dynamics, 123-137.

Schilpzand, P., Pater, I. E. De, \& Erez, A. (2016). Workplace incivility: A review of the literature and agenda for future research. Journal of Organizational Behavior ; 37(October), S57-S88.

https://doi.org/10.1002/job.1976

Shapiro, J. (2013). Workplace incivility at the daily level: the effects of rumination on performance and revenge motives. (University of Connecticut Graduate School). Retrieved from

http://digitalcommons.uconn.edu/cgi/viewcontent.cgi?a rticle $=1552 \&$ context $=$ gs_theses

Sleem, W. F., \& Seada, A. M. (2017). Role of Workplace Civility Climate and Workgroup Norms on Incidence of Incivility Behaviour among Staff Nurses. International Journal Of Nursing Didactics, 7(06).

Torkelson, E., Holm, K., Bäckström, M., \& Schad, E. (2016). Factors contributing to the perpetration of workplace incivility: the importance of organizational aspects and experiencing incivility from others. Work \& Stress, 30(2), 115-131.

Vagharseyyedin, S. A. (2015). Workplace incivility: a concept analysis. Contemporary Nurse, 50(1), 115-125. https://doi.org/10.1080/10376178.2015.1010262

Zhou, Z. (2014). Effects of Workplace Incivility on Nurses' Emotions, Well-being, and Behaviors: A Longitudinal Study (University of South Florida). Retrieved from http://scholarcommons.usf.edu/etd/5338 